\title{
ARTICLE
}

\section{Diagnosis of atopic dermatitis: From bedside to laboratory}

W Sinclair, ${ }^{1} \mathrm{MB}$ ChB, MMed (Derm); J Aboobaker, ${ }^{2} \mathrm{MB}$ ChB, FFDerm (SA), FRCP (Lond), PhD;

R J Green, ${ }^{3}$ MB BCh, DCH, FCP (SA), DTM\&H, MMed, FCCP, PhD, Dip Allergology (SA), DSc;

M E Levin, ${ }^{4} \mathrm{MB}$ ChB, FCPaed (SA), Dip Allergology (SA), MMed (Paed), PhD, EEACI (UEMS), FAAAAI, FACAAI

${ }^{1}$ Department of Dermatology, Faculty of Health Sciences, University of the Free State, Bloemfontein, South Africa

${ }^{2}$ Department of Dermatology, University of KwaZulu-Natal, Durban, South Africa

${ }^{3}$ Department of Paediatrics and Child Health, Faculty of Health Sciences, University of Pretoria, South Africa

${ }^{4}$ Division of Asthma and Allergy, Department of Paediatrics, Faculty of Health Sciences, University of Cape Town and Red Cross War Memorial Children's Hospital, Cape Town, South Africa

Corresponding author: W Sinclair (sinclairw@ufs.ac.za)

Atopic dermatitis $(\mathrm{AD})$ is essentially diagnosed clinically. In babies and young children, the diagnosis is usually straightforward. Dry, very pruritic dermatitis starts on the cheeks, with the neck and trunk often involved, but the nappy area spared. Limb involvement follows later - first extensoral, later classically flexural. This is mostly the picture of AD. In adults, the presentation may vary widely. Classic flexural dermatitis may persist, but erythroderma (whole-body involvement), head and neck dermatitis, isolated hand dermatitis and nummular dermatitis may be more difficult to identify as AD.

S Afr Med J 2014;104(10):711. DOI:10.7196/SAMJ.8850

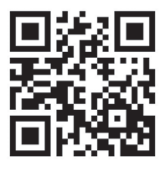

\section{Clinical diagnosis of atopic} dermatitis

The diagnosis of atopic dermatitis $(\mathrm{AD})$ is often not straightforward, especially in adults. Young babies who present with typically dry pruritic dermatitis in the classic distribution according to the age of the child are easy to diagnose. ${ }^{[1]}$ Several other conditions have to be considered in the differential diagnosis, as discussed below. Where the disease represents a mere continuation of $\mathrm{AD}$ since childhood, the diagnosis is usually easy and the clinical picture typical. With onset $>18$ years of age (adult-onset $\mathrm{AD}$ ), the disease pattern is often not obvious, although it may still present with the usual flexural dermatitis seen in children. Non-typical morphological features and localisation are common with nummular, prurigo-like, follicular and seborrhoeic patterns that are often seen. ${ }^{[2]}$ In adults, erythroderma is a rare manifestation of AD. ${ }^{[3]}$ The physical and environmental factors for adults differ from those for children and are responsible for the different patterns of involvement.

\footnotetext{
Table 1. Revised criteria for the diagnosis of atopic dermatitis ${ }^{[5]}$

Must have:

Pruritus/itching

Plus three or more of the following:

History of flexural dermatitis (front of elbows, back of knees, front of ankles, neck, around the eyes) or involvement of cheeks and/or extensor surfaces in children aged $>18$ months

Visible flexural dermatitis involving the skin creases (or the cheeks and/or extensor surfaces in children aged $>18$ months)

History of a dry skin in the past year

History of asthma or hay fever (or atopic disease in a first-degree relative in children $<4$ years of age)

Onset $<2$ years (for children aged $\geq 4$ years at time of diagnosis)
}

The traditional criteria set out by Hanifin and Rajka ${ }^{[4]}$ are used less frequently than before. Williams et al. (UK Working Party) ${ }^{[5]}$ developed a revised set of criteria, which was validated in the hospital setting ${ }^{[6]}$ and in the community. ${ }^{[7]}$ According to this group, these criteria should be adopted for the diagnosis of $\mathrm{AD}$, even though a recent study ${ }^{[8]}$ in children has shown that these criteria are not reliable when applied to low-prevalence populations, i.e. the amaXhosa in South Africa. The criteria are set out in Table 1.

The histological findings on skin biopsy may be suggestive of the diagnosis, but generally cannot be relied on to make the diagnosis. ${ }^{[5]}$

Total serum IgE levels are significantly raised in about $50 \%$ of cases and normal in the rest, reducing their value in the diagnosis. The IgE level does not correlate with the severity of the dermatitis, and 15\% of non-atopic individuals have raised IgE levels.

Several conditions have to be considered in the differential diagnosis of $\mathrm{AD}$ (Table 2). These have to be excluded clinically and by appropriate investigations.

Table 2. Differential diagnosis of atopic dermatitis

- Seborrhoeic dermatitis

- Discoid (nummular) dermatitis

- Irritant contact dermatitis (especially of the hands)

- Allergic contact dermatitis and airborne contact dermatitis

- Photo-allergic and photo-irritant dermatitis

- 'HIV dermatitis'

- Drug-induced dermatitis

- Cutaneous T-cell lymphoma

- Psoriasis, especially the erythrodermic type

- Scabies

- Insect bites

- Filariasis 


\section{Measuring the severity of atopic dermatitis}

The severity of dermatitis can be measured and monitored in several ways. The SCORing Atopic Dermatitis (SCORAD) index, ${ }^{[9]}$ the Objective Severity Assessment of Atopic Dermatitis (OSAAD) ${ }^{[10-13]}$ and the Three Item Severity Score ${ }^{[14]}$ all have merit in a research context, but are not practical for daily clinical use.

It is the opinion of the authors that the severity assessment should be simplified, with the objective to stratify treatment accordingly in individual patients. We propose:

- Measuring the area involved in percentage of body surface, where $1 \%$ body surface approximates the size of one of the patient's hands (including the fingers).

- Establishing acute, subacute or chronic changes, where acute changes would imply more severe dermatitis. ${ }^{[1]}$

- Determining the impact on the patient's quality of life (e.g sleep disturbances, absenteeism, visible scratch marks, social withdrawal).

Dermatitis can then be classified and treated as mild, moderate or severe as outlined below.

A flare of dermatitis can be defined as any episode of upgrading of the dermatitis, e.g. from mild to moderate (Table 3).

Table 3. Assessment of the severity of atopic dermatitis

Mild: $<5 \%$ body surface involved

No acute changes

No significant impact on quality of life

Moderate: 5 - 30\% body surface involved

Mild dermatitis with acute changes

Mild dermatitis with significant impact on quality of life

Severe: $>30 \%$ body surface involved

Moderate dermatitis with acute changes

Moderate dermatitis with significant impact on quality of life

\section{Special investigations}

To diagnose $\mathrm{AD}$, special investigations are rarely necessary, but may be performed mainly to identify trigger factors that flare up or aggravate the condition so that patients may be advised to avoid these. However, these investigations are useful in the management of $\mathrm{AD}$, mostly in children. ${ }^{[15,16]}$

A skin biopsy is done occasionally and may be useful in an adult with generalised exfoliative erythroderma in order to differentiate it from other causes of erythroderma. ${ }^{[15]}$

Total serum IgE estimation, ImmunoCAP assays for specific IgE and skin-prick tests may be done to confirm the atopic nature of a patient's condition.

The skin-prick test is the most common procedure used to confirm food and inhaled aeroallergen sensitisation. Either commercially available extracts or fresh foods may be used, mostly cow's milk, hen's egg, wheat, soy, fish and peanuts. Aeroallergens (mites, pollens, moulds, and animal dander) may be tested in the same way. Commercial extracts are placed directly on the skin, which is pricked through the liquid. Aqueous fresh foods (or solid native foods crushed with saline) may be tested similarly. Solid native foods such as fruit may also be tested by pricking the food with a lancet and then pricking the skin - the 'prick-prick test'. A new lancet should be used for each skin prick. The test site is observed for 15 - 20 minutes and the mean wheal reaction (largest diameter $+90^{\circ} \div 2$ ) measured and recorded in millimetres. A positive control with histamine should be $\geq 3 \mathrm{~mm}$; a negative control with saline is also done. ${ }^{[17-20]}$

Variants of the skin-prick test include the scratch patch test, where the skin is scratched and the food applied under an occlusive patch, and the skin application test, where the food is applied to the skin without scratching and examined at 10-minute intervals for a reaction. These tests are not commonly used as they add no additional value to the routine test. ${ }^{[19,20]}$

Immediate-type (IgE-mediated) food allergy is diagnosed by taking a thorough history, performing tests, looking for specific IgE sensitisation by means of the tests mentioned above and performing oral food challenges if indicated. Negative skin and ImmunoCAP tests are useful for excluding an immediate-type reaction, but cannot exclude a delayed-type reaction.

Positive tests indicating sensitisation are not necessarily related to food allergy. The predictive values for a history of a food reaction, positive skin-prick test and positive food-specific IgE in isolation are poor for diagnosing food allergy in AD. The role of sensitisation must be interpreted together with the history, and in uncertain cases a food challenge test should be done to prove definite food allergy or food tolerance. If the diagnosis is not clear or the clinical relevance of a positive food allergy test is not certain, a food challenge test should be performed. Specific methods for food challenge testing are available from the authors.

In adults with head and neck dermatitis a positive ImmunoCAP assay to Malassezia species may be useful, as such patients may benefit from treatment with oral anti-yeast treatment. ${ }^{[15,16]}$

Patch tests involve formal testing to diagnose superimposed allergic contact dermatitis, e.g. in adult patients with chronic hand dermatitis. The aetiology of the continuing dermatitis is elucidated. ${ }^{[15]}$ Formal patch tests are also useful for deteriorating dermatitis that is being intensively treated, as the patient may have an allergic contact dermatitis to one of the components of the current topical treatment. ${ }^{[15]}$

The atopy patch test is used to diagnose type IV hypersensitivity reactions and determine food and aeroallergen triggers for dermatitis. It is a specialised, time-consuming procedure that is highly specific, but with lower levels of sensitivity, ${ }^{[19]}$ not often used in adults with $\mathrm{AD} .^{[15,16,18,19]}$

In cases of suspected immunodeficiency, tests such as human T-lymphotropic virus type 1 (HTLV-1), HIV, immunoglobulin subtypes, T- and B-cell numbers and functions will need to be done. If secondary bacterial infections are suspected, pus swabs will be necessary. A suspected herpes infection may be confirmed by a Tzanck smear, a rapid polymerase chain reaction test done on a dry swab or electronmicroscopy. ${ }^{[15]}$

\section{References}

1. Jordaan HF, Todd G, Sinclair W, Green R. Aetiopathogenesis of atopic dermatitis. S Afr Med J 2014;104(10):706-709. [http://dx.doi.org/10.7196/SAMJ.8840]

2. Ozkaya E. Adult-onset atopic dermatitis. J Am Acad Dermatol 2005;52:579-582. [http://dx.doi. org/10.1016/j.jaad.2004.11.037]

3. Rym BM, Mourad M, Bechir Z, et al. Erythroderma in adults: A report of 80 cases. Int J Dermatol 2005;44(9):731-735. [http://dx.doi.org/10.1111/j.1365-4632.2004.02100.x]

4. Hanifin JM, Rajka G. Diagnostic features of atopic dermatitis. Acta Derm Venereol Suppl (Stockh) 1980;92:44-47.

5. Williams HC, Burney PG, Hay RJ, et al. The UK Working Party's diagnostic criteria for atopic dermatitis. I. Derivation of a minimum set of discriminators for atopic dermatitis. Br J Dermatol 1994;131:383-396. [http://dx.doi.org/10.1111/j.1365-2133.1994.tb08530.x]

6. Williams HC, Burney PG, Pembroke AC, Hay RJ. The UK Working Party's diagnostic criteria for 作 org/10.1111/j.1365-2133.1994.tb08532.x]

Williams HC, Burney PG, Strachan D, Hay RJ. The UK Working Party's diagnostic criteria for atopic dermatitis. II. Observer variation of clinical diagnosis and signs of atopic dermatitis. Br J Dermatol 1994;131:397-405. [http://dx.doi.org/10.1111/j.1365-2133.1994.tb08531.x]

. Chalmers DA, Todd G, Saxe N, et al. Validation of the UK Working Party diagnostic criteria for atopic eczema in a Xhosa-speaking African population. Br J Dermatol 2007;156(1):111-116. [http://dx.doi.

9. European Task Force on Atopic Dermatitis. Severity scoring of atopic dermatitis. The SCORAD index Consensus report of the European Task Force on Atopic Dermatitis. Dermatology 1993;186:23-31. [http://dx.doi.org/10.1159/000247298] 


\section{CONTINUING MEDICAL EDUCATION}

10. Sugarman J, Fluhr J, Fowler A, et al. The Objective Severity Assessment Atopic Dermatitis score. Arch Dermatol 2003;139:1417-1422

1. Angelova-Fischer I, Bauer A, Hipler UC, et al. The Objective Severity Assessment of Atopic Dermatitis (OSAAD) score: Validity, reliability and sensitivity in adult patients with atopic dermatitis. $\mathrm{Br}$ Dermatol 2005;153:767-773. [http://dx.doi.org/10.1111/j.1365-2133.2005.06697.x]

12. Frezzolini A, Paradisi M, Faffiro A, et al. Circulating interleukin-16 (Il-16) in children with atopic cezema/deratis syndrome 2002;57:815-820.

13. Masuda K, Katoh N, Okuda F, Kishimoto S. Increased levels of serum interleukin-16 in adult type atopic dermatitis. Acta Derm Venereol 2003;83:49-53. [http://dx.doi.org/10.1080/00015550310016472]

4. Charman CR, Venn AJ, Williams HC. Measuring atopic eczema severity visually: Which variables are mos important to patients? Arch Dermatol 2005;141(9):1146-1151. [http://dx.doi.org/10.1001/archderm.141.9.1146 15. Friedmann PS, Arden-Jones MR, Holden CA. Atopic dermatitis. In: Burns T, Breathnach S, Cox N
Griffiths C, eds. Rooks Textbook of Dermatology. 8th ed Chichester. UK. Wiley Blackwell Publishers 2010:24.27-24.28. [http://dx.doi.org/10.1002/9781444317633.ch24]

16. Katsarou A, Armenaka MC. Atopic dermatitis in older patients: Particular points. J Eur Acad Dermato Venereol 2011;25(1):12-18. [http://dx.doi.org/10.1111/j.1468-3083.2010.03737.x]

. Čelakovská J, Ettlerová K, Ettler K, Vaněčková J. Egg allergy in patients over 14 years old suffering from atopic eczema. Int I Dermatol 2011;50(7):811-818. [http://dx.doi.org/10.1111/j.1365-4632.2010.04780.x 18. Suh KY. Food allergy and atopic dermatitis: Separating fact from ficton. Semin Cutan Med Surg 2010;29(2):72-78. http://dx.doi.org/10.1016/j.sder.2010.03.007]

9. Čelakovská J, Ettlerová K, Ettler K, Vaněčková J. Atopy patch test in diagnosis of food allergy to egg in adul patients suffering from atopic eczema. Three case reports. Acta Medica (Hradec Kralove) 2011;54(1):29-35. 20. Bath-Hextall F, Delamere FM, Williams HC. Dietary exclusion for improving established atopic eczema in adults and children: Systematic review. Allergy 2009;64(2):258-264. [http://dx.doi.org/10.1111/j.1398 9995.2008.01917.x 